\title{
EDITORIAL
}

\section{El necesario fortalecimiento de la investigación en salud pública}

La producción científica, logros y desafíos de la salud pública nacional comparten las vicisitudes del desarrollo científico nacional, la condición de las universidades y los problemas en la docencia y la investigación. Se agregan en este ámbito las dificultades para avanzar en el perfeccionamiento de las políticas públicas en salud y las perturbaciones de las organizaciones prestadoras de servicios, tensionadas por presupuestos, sistemas de incentivos, metas, precios, costos, acceso, calidad, regulaciones.

Dada esa evidente y apremiante situación y las dificultades para el debate público y la construcción de acuerdos, cualquier alternativa de trabajo ha de enfatizar la búsqueda de evidencia contrastable, el desarrollo de métodos comparables, la verificación de hipótesis y la divulgación comprensible de resultados.

Ello requiere el fortalecimiento de la investigación en salud pública con el fin de multiplicar y potenciar el esfuerzo realizado en lo que concierne a la comunicación científica y el trabajo editorial. Nuestra revista ha vivido sus propias conmociones y, por ello, se han realizado cambios tanto en el Comité Ejecutivo como Editorial orientados a relanzar un proyecto que tiene ya 15 años de existencia.

\section{Fortalecer la comunidad de investigadores}

La modesta pretensión de contribuir al desarrollo y fortalecimiento de la salud pública en el país pretende continuar con la labor realizada hasta aquí por la revista y actualizarla en cuatro aspectos:

- Mejorar la calidad y cantidad de la producción que aparece en la revista: El propósito central es poner esta revista al servicio de la comunidad científica en salud pública y de todos los interesados en la investigación y producción de evidencia en nuestra área. Esto significa fortalecer el trabajo de redacción y comunicación científica especificando con mayor precisión criterios editoriales, reglas, condiciones y tiempos, sobre todo en cuanto a revisión de artículos. Así como ampliar nuestra red de arbitraje entre pares. La composición de un nuevo comité editorial, sus responsabilidades y tareas deben expresamente orientarse en esa perspectiva.

- Gestión editorial on line: Nos comprometemos a iniciar la recepción, revisión y edición a través de nuestra plataforma www.revistas.uchile.cl a partir del primer número del año 2012. Este proceso permitirá sentar las bases de un trabajo regular, organizado y oportuno.

- Indexación en Scielo: Ambos considerandos previos deben permitir someternos a la evaluación Scielo para indexación en el horizonte mediato. La condición de revista científica -que busca responder a una demanda urgente y mínima de quienes publican con nosotros- requiere un trabajo sostenido y el cumplimiento de requisitos, razón por la cual esos plazos deben ser establecidos a partir de un período de trabajo del equipo editorial actual para fortalecer la red de intercambios: Hemos iniciado un trabajo personalizado de convocatoria en las instituciones académicas, a nivel nacional y especialmente latinoamericano, de artículos, revisores y editores, así como de temas, propuestas y convergencias. 


\section{Nuestra disposición}

Con esas consideraciones queremos enfatizar la voluntad de establecer un contacto directo del editor con los autores y lectores para conversar sobre contenidos temáticos, aclaración de criterios, tareas, reuniones y toda suerte de iniciativas que potencien la investigación y la comunicación científica en salud pública. Tenemos confianza en que es posible encantar a la comunidad de salud pública invitándola a comunicar y a publicar y, con ello, contribuir a mejorar las condiciones de salud en nuestro país y en la Región.

Giorgio Solimano

Director

Yuri Carvajal

Editor 